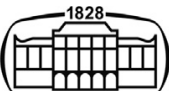

AKADÉMIAI KIADÓ

\title{
Motivated attention to stimuli related to social networking sites: A cue-reactivity study
}

\author{
TANIA MORETTA* * and GIULIA BUODO 주
}

\section{Journal of Behavioral Addictions}

10 (2021) 2, 314-326

DOl:

10.1556/2006.2021.00040

(c) 2021 The Author(s)

\section{FULL-LENGTH REPORT}

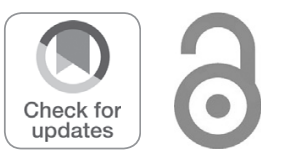

*Corresponding author. Tel.: +39049 8276957.

E-mail: tania.moretta.1@unipd.it
Department of General Psychology, University of Padova, Padova, Italy

Received: November 20, 2020 • Revised manuscript received: March 30, 2021 • Accepted: May 27, 2021

Published online: June 21, 2021

\begin{abstract}
Background and aims: It has been argued that similar to addictive behaviors, problematic Social Network sites use (PSNSU) is characterized by sensitized reward processing and cue-reactivity. However, no study to our knowledge has yet investigated cue-reactivity in PSNSU. The present study aims at investigating cue-reactivity to Social Network sites (i.e., Facebook)-related visual cues in individuals identified as problematic vs. non-problematic Facebook users by the Problematic Facebook Use Scale. Methods: The Event-Related Potentials (ERPs) were recorded during the passive viewing of Facebookrelated, pleasant, unpleasant, and neutral pictures in 27 problematic and 26 non-problematic users. Moreover, craving for Facebook usage was collected using a Likert scale. Results: Despite problematic users were more likely to endorse higher craving than non-problematic ones, Facebook-related cues elicited larger ERP positivity (400-600 ms) than neutral, and comparable to unpleasant stimuli, in all Facebook users. Only in problematic users we found larger positivity $(600-800 \mathrm{~ms})$ to pleasant than unpleasant cues and higher craving to be related with lower later positivity $(800-1,000 \mathrm{~ms})$ to pleasant and unpleasant cues. Discussion: Regardless of whether Facebook usage is problematic or non-problematic, Facebook-related cues seem to be motivationally relevant stimuli that capture attentional resources in the earlier stages of "motivated" attentional allocation. Moreover, our results support the view that in higher-craving problematic users, reduced abilities to experience emotions would be the result of defective emotion regulation processes that allow craving states to capture more motivational/attentional resources at the expense of other emotional states.
\end{abstract}

\section{KEYWORDS}

cue-reactivity, addictive behaviors, internet, event-related potentials, Facebook, craving

\section{INTRODUCTION}

Recent research argues that social networking sites (SNSs) are potentially addictive and their problematic use (i.e., Problematic Social Network Sites Use, PSNSU) shares core components with substance use disorders (SUDs) and behavioral addictions, i.e. salience, tolerance, mood modification, conflict, withdrawal, problems, and relapse (Griffiths, Kuss, \& Demetrovics, 2014).

Despite it is not included in any established diagnostic classification of mental disorders, PSNSU has been defined as "being overly concerned about SNSs, to be driven by a strong motivation to $\log$ on to or use SNSs, and to devote so much time and effort to SNSs that it impairs other social activities, studies/job, interpersonal relationships, and/or psychological health and well-being" (Andreassen \& Pallesen, 2014). While some scholars have argued that there may be unique factors associated with the use and abuse of specific SNSs (i.e., Facebook; Ryan, Chester, Reece, \& Xenos, 2014), the dominant view conceptualizes PSNSU as an addictive behavior characterized by compulsive use of the social, communicative activity rather than specific application or device (Wegmann \& Brand, 2019). In this perspective, Problematic Facebook Use (PFU) would be only one example of PSNSU (Kuss \& Griffiths, 2011, 2017).

To the best of our knowledge, only a few studies have investigated the neural correlates of PSNSU (He, Turel, \& Bechara, 2017; Horvath et al., 2020; Turel, He, Xue, Xiao, \& Bechara, 
2014) and only one theoretical model explicitly includes psychobiological factors implicated in PSNSU as a specific type of Internet-use disorder (Brand, Young, Laier, Wölfling, \& Potenza, 2016). This model suggests that similarly to addictions, PSNSU may involve an interaction of sensitized reward processing and cue-reactivity with defective prefrontal inhibitory control.

Cue-reactivity refers to the specific pattern of subjective and physiological responses shown by addicted individuals when they are confronted with addiction-relevant cues. Cuereactivity depends on learning mechanisms, i.e., in the case of SUDs various cues become associated with the rewarding properties of the drug (Hyman, Malenka, \& Nestler, 2006); in the case of gambling, gaming, and buying disorders addiction-relevant cues become associated with the addictive behavior (Starcke, Antons, Trotzke, \& Brand, 2018). A commonly used cue-reactivity paradigm consists in the exposure to addiction-related and neutral cues while psychophysiological responses are recorded. The reactivity to addiction-related cues is quantified as increased responses to addiction-related than to neutral cues (Jasinska, Stein, Kaiser, Naumer, \& Yalachkov, 2014).

Craving for SNS is strongly connected to cue-reactivity (Leng et al., 2019; Wegmann, Ostendorf, \& Brand, 2018; Wegmann, Stodt, \& Brand, 2018). In the context of SUDs, craving has been described as a difficult-to-resist urge to consume a substance, resulting from the repeated exposure to conditioned addiction-related stimuli that trigger cue-reactivity (Carter \& Tiffany, 1999). However, the difference between reactivity to addiction-related and neutral cues seems to not be sufficient to conclude that psychophysiological responses to addiction-related cues are exaggerated. A further comparison with motivationally relevant, non-addictionrelated stimuli that would engage the activity of appetitive and aversive motivational systems is necessary, as it would provide a stronger test of whether addiction-related cues hijack brain motivational systems and motivate addictive behaviors over alternative ones (Versace et al., 2017).

The concepts of cue-reactivity and craving have been transferred from SUDs to behavioral addictions, showing several similarities between these two groups of disorders (Starcke et al., 2018). Specifically, compared with healthy controls, individuals with gambling, gaming, buying disorders (Starcke et al., 2018) and smartphone addiction (Schmitgen et al., 2020) show higher reactivity to addictionrelated cues. Despite the similarities between PSNSU and addictive behaviors, no study to our knowledge has yet included behavioral and electrophysiological measures to investigate cue-reactivity in individuals with PSNSU.

Given their sensitivity to the neural responses elicited by affective stimuli, the event-related potentials (ERPs) can provide a noninvasive tool to study attentional and motivational processes in real-time during exposure to addictionrelated and emotional stimuli (e.g., Versace et al., 2011, 2017). Long-latency positive ERP components, the P3 and the Late Positive Potential (LPP) reflect sustained attention, representation of stimuli in short-term memory, or meaning evaluation (Hajcak, MacNamara, \& Olvet, 2010). In emotion research, larger parietal positivity following emotional compared to neutral stimuli has been taken to reflect "motivated attention", i.e., emotion automatically directs attention and thereby facilitates subsequent processing (e.g, Bradley et al., 2003). Moreover, the Early Posterior Negativity (EPN) component of the ERPs has been largely assessed in response to emotional stimuli as an index of early selective encoding of affective information (e.g., Schupp, Markus, Weike, \& Hamm, 2003).

The P3 component of the ERPs (peaking around $300 \mathrm{~ms}$ after stimulus onset) is larger in response to pleasant and unpleasant relative to neutral stimuli, with the most arousing stimuli eliciting the largest P3 amplitudes (Hajcak, MacNamara, \& Olvet, 2010). The LPP is a positive, sustained shift reaching its maximum amplitude about 700-1,000 ms after the presentation of motivationally relevant stimuli (Cuthbert, Schupp, Bradley, Birbaumer, \& Lang, 2000). This effect is more pronounced for highly arousing stimuli (Schupp et al., 2004). Cue-reactivity research on individuals with SUDs showed enhanced P3 and LPP amplitudes in response to addiction-related than to neutral pictorial stimuli (e.g., Littel, Euser, Munafò, \& Franken, 2012). Studies including also EPN have shown inconsistent evidence for cue-reactivity in SUD (Dunning et al., 2011; Versace et al., 2011) and no study to our knowledge has yet investigated these ERP components during a cue-reactivity task in PSNSU.

The present study aims at investigating cue-reactivity to Social Network sites (i.e., Facebook)-related visual cues in individuals classified as problematic vs. non-problematic Facebook users.

We hypothesized that in problematic Facebook users, Facebook-related pictures, a category of stimuli that may have acquired motivational significance by being repeatedly associated with the rewarding proprieties of using Facebook, would elicit larger P3 and LPP amplitudes than neutral pictures, and larger than in non-problematic Facebook users. Possibly, Facebook-related stimuli may have acquired as many rewarding properties as to elicit comparable neural responses to those elicited by high arousal pleasant stimuli. For exploratory purposes, the emotional modulation of EPN amplitude was also investigated.

We also expected problematic Facebook users to endorse higher craving ratings for Facebook usage than non-problematic Facebook users, and to rate Facebook-related pictures as more pleasant and arousing than neutral pictures, and than non-problematic Facebook users. Possibly, problematic Facebook users may rate Facebook-related and higharousal pleasant stimuli as comparably pleasant and arousing.

\section{METHOD}

\section{Participants}

Undergraduates were contacted informally at university facilities and asked to fill in an online version of the 
Problematic Facebook Use Scale (PFUS; Marino et al., 2017). The PFUS is a 15-item scale adapted from the Generalized Problematic Internet Use Scale 2 (Caplan, 2010). It includes five subscales, i.e., preference for online social interaction, mood regulation, cognitive preoccupation, compulsive use, and negative outcomes. Scores range from 15 to 120 , with higher scores indicating the presence of relevant Facebook use-related symptomatology. The Italian version of the PFUS has shown a good construct and convergent validity (Marino, Vieno, Altoè, \& Spada, 2017).

Based on the percentiles of the PFUS scores in Italian young adults (Moretta \& Buodo, 2018), 27 participants who scored equal to or higher than 41 (i.e., the 75th percentile) were included in the problematic Facebook users (PFUs) group. Twenty-seven participants who scored equal to or lower than 23 (i.e., the 25 th percentile) were included in the non-PFUs group. One participant in the non-PFUs group was excluded because of technical problems (see the Method section). The final non-PFUs group was thus composed of 26 participants. We chose to adopt the extreme-groups approach because it provides clear advantages in terms of cost-efficiency and statistical power (Preacher, Rucker, MacCallum, \& Nicewander, 2005) and because our focus was on comparing individuals with high vs. low problematic Facebook use, rather than on considering individuals with scores close to the median of the distribution. If we did test the same number of participants without performing any selection, chances were that the greatest part of the sample would have scored close to the median of the distribution and, thus, we would not have been able to observe the extremes. However, as the extreme-groups approach has the limit of treating individuals assigned to a group as identical on the categorizing variable, thus losing information about more subtle individual differences (Preacher et al., 2005), we also performed correlational analyses between P3 and LPP amplitudes and subjective ratings of Arousal and Valence for each emotional category in PFU and non-PFU.

As reported in Table 1, the two groups significantly differed on PFUS total scores and each PFUS subscale. Of note, PFUs reported mean scores of compulsive use and negative outcome subscales higher than the 75th percentile of the PFUS scores in Italian young adults (Moretta \& Buodo, 2018), while non-PFUs reported mean scores equal to the $25^{\text {th }}$ percentile. The two groups were comparable for sex distribution, age, and sleep hours.

\section{Craving measure}

To assess craving for Facebook use, participants were asked to respond to a question ("How much would you like to use Facebook now?") using a Likert scale (range $1-5 ; 1=$ not at all, 5 = very much).

\section{The passive picture viewing task}

Ninety-six digitized color pictures $(600 \times 800$ pixels $)$ were presented, divided into Facebook-related, unpleasant (attacking humans), pleasant (erotic couples), and neutral (people) taken from the International Affective Picture
System, IAPS (Lang, Bradley, \& Cuthbert, 2008) ${ }^{1}$. Pleasant and unpleasant pictures were matched for normative (high) arousal ratings (unpleasant $=6.25 \pm 0.61$; pleasant $=6.41 \pm$ $0.33 ; \mathrm{p}=0.47$ ), which were higher than for neutral pictures (neutral $=3.29 \pm 0.46 ; \mathrm{p}_{\mathrm{s}}<0.001$ ). Pleasant and unpleasant pictures different significantly for mean normative valence ratings (pleasant $=6.63 \pm 0.38$; unpleasant $=2.61 \pm 0.45, \mathrm{p}$ $<0.001$ ), which were higher and lower, respectively, than for neutral pictures (neutral $=5.04 \pm 0.41 ; \mathrm{p}_{\mathrm{s}}<0.001$ ). Facebook-related pictures depicted one or more persons using Facebook. They were downloaded from websites and digitally edited so that all pictures had the same pixel resolution.

Each picture was presented for 4 seconds and was followed by a variable intertrial interval (ITI, a black background with a white fixation cross) of 4-5 seconds. The order of picture presentation was pseudo-randomized so that no two pictures of the same category were presented in succession. The pictures were presented three times each. The experimental session was divided into three blocks counterbalanced between participants, who could rest between blocks. The entire picture presentation lasted approximately 30 minutes. During picture viewing and ITIs, a startle probe was delivered binaurally at $300,1,500$, or $3,500 \mathrm{~ms}$ after picture onset. Since the P3 and the LPP develop between 400 and 1,000 ms after picture onset, trials, where the startle probe was presented at $300 \mathrm{~ms}(1 / 3$ of the trials), were not included in ERP analysis. Pictures were presented on a 19-inch computer screen through a Core i54440 computer running E-prime presentation software (version 2.0, Psychology Software Tools, Pittsburgh, PA, USA), at a viewing distance of $1 \mathrm{~m}$.

After picture presentation, participants were asked to rate 12 pictures for each category used for the viewing task, using a computerized version of the 1-9 point scales of Valence and Arousal of the Self-Assessment Manikin (SAM; Bradley \& Lang, 1994).

\section{Physiological recording}

The electroencephalogram (EEG) was recorded using an elastic cap with 32 tin electrodes (ANT Neuro Company) arranged according to the 10-20 System (Fp1, Fpz, Fp2, F7, F3, Fz, F4, F8, FC5, FC1, FC2, FC6, T7, C3, Cz, C4, T8, CP5, CP1, CP2, CP6, P7, P3, Pz, P4, P8, POz, O1, Oz, O2, and M1 and M2 [mastoids]), referenced online to $\mathrm{Cz}$. Both vertical and horizontal electrooculograms (EOGs) were recorded using a bipolar montage. The electrode pairs were placed at the supra- and suborbit of the right eye and the external canthi of the eyes, respectively.

${ }^{1}$ The IAPS picture numbers were as follows: Pleasant: 4611. 4647, 4650, 4651, 4652, 4656, 4658, 4659, 4660, 4664, 4666, 4669, 4670, 4672, 4676, 4680, 4681, 4683, 4687, 4690, 4694, 4695, 4800, 4810. Unpleasant: 2683, 2691, 3500, 6211, 6212, 6213, 6242, 6243, 6244, 6250, 6260, 6312, 6313, $6315,6350,6510,6540,6550,6560,6561,6571,6821,6836,9425$. Neutral: $2038,2102,2104,2190,2191,2210,2214,2215,2372,2381,2383,2393$, 2396, 2480, 2485, 2493, 2495, 2514, 2570, 2575, 2580, 2593, 2850, 8010. 
Table 1. Descriptive statistics and differences between Problematic (PFUs) and non-problematic (non-PFUs) Facebook users

\begin{tabular}{lcccc}
\hline & Non-PFUs $(\mathrm{n}=26)$ & PFUs $(\mathrm{n}=27)$ & Test-statistic & $\mathrm{p}$-value \\
\hline PFUS total score & $19.2( \pm 2.5)$ & $46.9( \pm 9.1)$ & $15.0^{\mathrm{t} \text {-test }}$ & $<0.001$ \\
POSI score & $3.5( \pm 1.1)$ & $8.2( \pm 4.1)$ & $5.50^{\text {t-test }}$ & $<0.001$ \\
Mood regulation score & $5.1( \pm 1.9)$ & $12.7( \pm 3.7)$ & $9.41^{\mathrm{t} \text {-test }}$ & $<0.001$ \\
Cognitive preoccupation score & $3.5( \pm 1.0)$ & $7.7( \pm 2.2)$ & $8.92^{\text {t-test }}$ & $<0.001$ \\
Compulsive use score & $4.0( \pm 1.7)$ & $12.2( \pm 4.5)$ & $8.62^{\mathrm{t} \text { test }}$ & $<0.001$ \\
Negative outcomes score & $3.1( \pm 0.3)$ & $6.3( \pm 2.9)$ & $5.59^{\text {t-test }}$ & $<0.001$ \\
Sex (F/M) & $21 / 5$ & $18 / 9$ & $1.15^{\mathrm{Glm} \text { - } \text {-test }}$ & 0.24 \\
Age & $23.4( \pm 3.2)$ & $7.1( \pm 0.8)$ & $0.12^{\mathrm{t} \text {-test }}$ & 0.91 \\
Sleep hours & $7.3( \pm 0.7)$ & $1.3( \pm 3.3)$ & $-1.14^{\text {t-test }}$ & 0.26 \\
Cigarette consumption & $2.3( \pm 3.8)$ & $85.8( \pm 43.8)$ & $3.42^{\text {t-test }}$ & 0.30 \\
Minutes on Facebook & $45.9( \pm 29.3)$ & $0.7( \pm 2)$ & $5.84^{\chi 2}$ test & 0.001 \\
Self-reported craving & $0.2( \pm 0.37)$ & 0.02 \\
\hline
\end{tabular}

Legend: PFUS = Problematic Facebook Use Scale; POSI = Preference for Online Social Interaction; Glm = generalized linear model with binomial error distribution. Sleep hours, cigarette consumption, and minutes on Facebook $=$ quantities per day.

All electrophysiological signals were amplified with EEGO amplifier (ANT Neuro Company, https://www.antneuro.com/products/eego_mylab). All electrode impedances were kept below $5 \mathrm{k} \Omega$. The EEG signal was bandpass filtered online (EEG filter $=0.1-40 \mathrm{~Hz}$ ) and digitized at $1,000 \mathrm{~Hz}$. Offline, the EEG was re-referenced to linked mastoids, corrected for eyeblink artifacts using independent component analysis, and low-pass filtered at $30 \mathrm{~Hz}$. Filtering and further EEG processing were run using Brain Vision Analyzer 2.1 software. The EEG was segmented off-line into 1100 -msec epochs, from $100 \mathrm{~ms}$ before to $1,000 \mathrm{~ms}$ after stimulus onset. The EEG epochs were baseline-corrected against the mean voltage during the 100 -ms prestimulus period. All EEG epochs were visually scored for eye movements and other artifacts, and each portion of data containing artifacts greater than $\pm 70 \mathrm{uV}$ in any channel was rejected for all the recorded channels before further analysis. One participant was removed from the study sample due to technical problems during data recording.

According to the literature (Cuthbert et al., 2000; Schupp et al., 2004, 2007) and visual inspection of the grand-average ERPs waveforms, mean amplitudes were calculated in the 280-400 ms time window for P3, and in three consecutive time windows for LPP, i.e., $400-600 \mathrm{~ms}$ (LPP1), $600-800 \mathrm{~ms}$ (LPP2), and 800-1,000 ms (LPP3) at F3, Fz, F4, C3, Cz, C4, $\mathrm{P} 3, \mathrm{Pz}, \mathrm{P} 4$. Moreover, for exploratory purposes, the mean amplitude of the EPN was calculated in the 200-280 ms time window, at $\mathrm{O} 1, \mathrm{PO}, \mathrm{Oz}, \mathrm{O} 2$.

Acknowledging the relative advantages of calculating mean vs. peak amplitude of ERP components (Luck, 2014), we only report and discuss mean amplitudes in the main text. For analyses on peaks and latencies see the Supplement.

\section{Procedure}

Participants were asked to report information about their demographic characteristics, health status, daily time spent on Facebook, sleep hours, daily cigarette consumption, and to rate their Facebook craving. Then, they were seated on a comfortable chair in a dimly lit, sound-attenuated room.
After electrode attachment and a 10-min adaptation period, six neutral pictures were presented as practice trials before the task. The entire procedure took about $80 \mathrm{~min}$.

\section{Statistical analysis}

All analyses were performed using R software (R Development Core Team, 2016).

As the groups differed significantly in time spent daily on Facebook (Cohen $\mathrm{d}=1.1$ ), with PFUs spending more time on Facebook than non-PFUs (see Table 1), this variable was included as a covariate in all analyses. Given the ordinal nature of the self-reported craving level, a cumulative link generalized linear model (Christensen, 2015) considering group (PFUs, non-PFUs) as a predictor was performed to compare craving levels between groups. Before running the other analyses, all data were examined for outliers and normalcy. The scatterplot of the standardized residuals showed that the data met the assumptions of homogeneity of variance and linearity for all dependent variables.

Separate linear mixed-effects models (LMMs) with individual random intercept (R package: lme4, Bates, Maechler, Bolker, \& Walker, 2014) were conducted on mean P3 and LPP1, LPP2, and LPP3 amplitudes, with Category (i.e., Facebook-related, Pleasant, Unpleasant, and Neutral), Group (PFUs and non-PFUs), Area (frontal [F3, Fz, F4], central $[\mathrm{C} 3, \mathrm{Cz}, \mathrm{C} 4]$, and parietal $[\mathrm{P} 3, \mathrm{Pz}, \mathrm{P} 4])$, Laterality (left $[\mathrm{F} 3, \mathrm{C} 3, \mathrm{P} 3]$, midline $[\mathrm{Fz}, \mathrm{Cz}, \mathrm{Pz}]$, right $[\mathrm{F} 4, \mathrm{C} 4, \mathrm{P} 4]$ ) and their interaction as fixed factors. Moreover, the interaction between Group $\times$ Category $\times$ Craving level was also assessed.

For exploratory purposes, an LMM with individual random intercept was also conducted on the mean EPN amplitude, with Group, Category, Site (POz; Oz; O1; O2) and their interaction as fixed factors. The interaction between Group $\times$ Category $\times$ Craving level was also assessed.

Valence and Arousal ratings were submitted to separate LMMs, with participants and pictures as random terms, and Category and Group as fixed factors. The strength of parameters evidence within the models was estimated as the 
difference in the Akaike information criterion ( $\triangle \mathrm{AIC}$, Wagenmakers \& Farrell, 2004). Denominator degrees of freedom were estimated by Satterthwaite and KenwardRoger methods (Kuznetsova, Brockhoff, \& Christensen, 2017). Bonferroni HSD post-hoc tests were employed to further examine significant effects $(p<0.05)$.

Lastly, Pearson's correlation coefficients were calculated between P3 and LPP amplitudes at Fz, Cz, Pz, and SAM ratings, separately for PFUs and non-PFUs. To correct for type I error rate, Bonferroni correction for multiple testing was applied and the alpha significance level was set on $\mathrm{p}<0.004$.

\section{Ethics}

The study procedures were carried out in accordance with the Declaration of Helsinki. The local Ethical Committee of Psychological Research approved the study. All subjects were informed about the study and all provided informed consent.

\section{RESULTS}

\section{Craving ratings}

PFUs were more likely to endorse higher self-reported craving for Facebook usage as compared with non-PFUs $(\mathrm{OR}=5.16$, Table 1$)$.

\section{ERPs}

P3. The significant main effect of Area $\left(F_{2,1569}=69.73, p<\right.$ $0.001, \Delta \mathrm{AIC}=532$ ) was specified by the significant Group $\times$ Area interaction $\left(\mathrm{F}_{2,1569}=3.67, \mathrm{p}=0.03, \Delta \mathrm{AIC}\right.$ $=14.4$ ), showing larger positivity in the Parietal than the Central and Frontal areas (ps $<0.05)$ and lower positivity in the Frontal than the Central area $(\mathrm{p}<0.05)$ in both groups. No between-group differences were found.

A significant main effect of Category $\left(\mathrm{F}_{3,1569}=69.73, \mathrm{p}\right.$ $<0.001, \Delta$ AIC $=248)$ was specified by the significant Category $\times$ Area interaction $\left(\mathrm{F}_{6}, 1569=2.83, \mathrm{p}=0.01\right.$, $\Delta \mathrm{AIC}=5.8)$, highlighting greater positivity for Pleasant than for all other picture categories $\left(\mathrm{p}_{\mathrm{s}}<0.001\right)$ only in Central and Frontal areas. Larger relative positivity for Neutral than for Facebook-related pictures was found $\left(\mathrm{p}_{\mathrm{s}}<\right.$ 0.05) in Central and Parietal areas. The amplitude for Unpleasant pictures was comparable to that for Neutral pictures in all areas. Overall, P3 amplitudes were larger in the Parietal than Central and Frontal areas for all picture categories (ps < 0.05) except for Facebook-related pictures, which elicited comparable P3 amplitudes in Central and Frontal areas. Of note, Category $\times$ Area interaction showed low strength of evidence as indicated by $\Delta$ AIC.

LPP1 (400-600 ms). The significant main effect of Laterality $\left(\mathrm{F}_{2,1569}=13.83, \mathrm{p}<0.001, \Delta \mathrm{AIC}=27.6\right)$ showed larger positivity on the right side than on the midline and the left side $\left(\mathrm{p}_{\mathrm{s}}<0.001\right)$.
The significant main effect of Area $\left(\mathrm{F}_{2,1569}=582.24, \mathrm{p}<\right.$ $0.001, \Delta$ AIC $=896$ ) highlighted larger positivity in the Parietal than Central and Frontal areas and the Central than Frontal area (all ps $<0.001$ ).

The significant main effect of Category $\left(\mathrm{F}_{3}, 1569=\right.$ 165.30, $\mathrm{p}<0.001, \Delta \mathrm{AIC}=513$ ) highlighted larger positivity for Facebook-related, Pleasant, and Unpleasant than for Neutral pictures ( $\mathrm{ps}<0.001$ ). The LPP1 amplitude was larger for Pleasant than for all other picture categories ( $\mathrm{ps}<$ 0.001). LPP1 amplitude for Facebook-related pictures was comparable to that for Unpleasant pictures.

LPP2 (600-800 ms). The significant main effect of Area $\left(\mathrm{F}_{2}\right.$, $\left.{ }_{1569}=259.20, \mathrm{p}<0.001, \Delta \mathrm{AIC}=471\right)$ was specified by the significant Category $\times$ Area interaction $\left(\mathrm{F}_{6}, 1569=2.39, \mathrm{p}=\right.$ $0.03, \Delta \mathrm{AIC}=24.4)$, highlighting in all areas greater positivity for Pleasant than for all other picture categories (ps < 0.001). Comparable positivity for Neutral and Facebookrelated pictures was also found. The amplitude for Unpleasant pictures was larger than that for Neutral and Facebook-related pictures. Overall, LPP2 amplitudes were larger in the Parietal than Central and Frontal areas for all picture categories (ps < 0.05).

The significant main effect of Category $\left(\mathrm{F}_{3}, 1569=\right.$ $210.48, \mathrm{p}<0.001, \Delta \mathrm{AIC}=572)$ was specified by the significant Group $\times$ Category interaction $\left(\mathrm{F}_{3,1569}=2.81, \mathrm{p}=\right.$ $0.04, \Delta \mathrm{AIC}=25)$. Both PFUs and non-PFUs showed larger positivity for Pleasant and Unpleasant than for Facebookrelated and Neutral pictures ( $\mathrm{ps}<0.001)$. However, PFUs showed larger positivity for Pleasant than for Unpleasant pictures $(\mathrm{p}<0.001)$, whereas non-PFUs showed comparable LPP2 amplitudes for Pleasant and Unpleasant pictures (see Figs 1 and 2).

LPP3 (800-1,000 ms). A significant main effect of Area $\left(\mathrm{F}_{2}\right.$, $\left.{ }_{1569}=41.45, \mathrm{p}<0.001, \Delta \mathrm{AIC}=62.8\right)$ was found. Lower LPP3 amplitude was observed in the parietal than in the central and frontal areas $\left(\mathrm{p}_{\mathrm{s}}<0.001\right)$. The amplitudes in the central and frontal areas did not differ from each other.

The significant main effect of Category $\left(\mathrm{F}_{3,1569}=59.58\right.$, $\mathrm{p}<0.001, \Delta \mathrm{AIC}=241)$ was specified by the significant Group $\times$ Category interaction $\left(\mathrm{F}_{3,1569}=4.95, \mathrm{p}=0.002\right.$, $\triangle \mathrm{AIC}=22.3$ ). Both PFUs and non-PFUs showed larger positivity for Pleasant than for Facebook-related and Neutral pictures $\left(\mathrm{p}_{\mathrm{s}}<0.05\right)$, and lower positivity for Facebookrelated than for Neutral pictures $(\mathrm{p}<0.001)$. However, PFUs showed larger positivity for Pleasant than for Unpleasant pictures $(p=0.002)$, whereas non-PFUs showed comparable LPP3 amplitudes for Pleasant and Unpleasant pictures (see Figs 1 and 2).

A significant Group $\times$ Category $\times$ Craving interaction $\left(\mathrm{F}_{8,151}=4.45, \mathrm{p}<0.001, \Delta \mathrm{AIC}=22.7\right)$ was also found. Only in PFU, the regression slope of Craving differed significantly from zero in predicting LPP3 amplitude for Unpleasant $(\beta=-1.26$, SE $=0.57,95 \% \mathrm{CI}=[-2.40$ to $-0.12])$ and Pleasant pictures $(\beta=-1.31, \mathrm{SE}=0.57,95 \%$ $\mathrm{CI}=[-2.45$ to -0.17$])$ so that higher Craving predicted lower LPP3 in response to Pleasant and Unpleasant pictures. 
non-PFUs
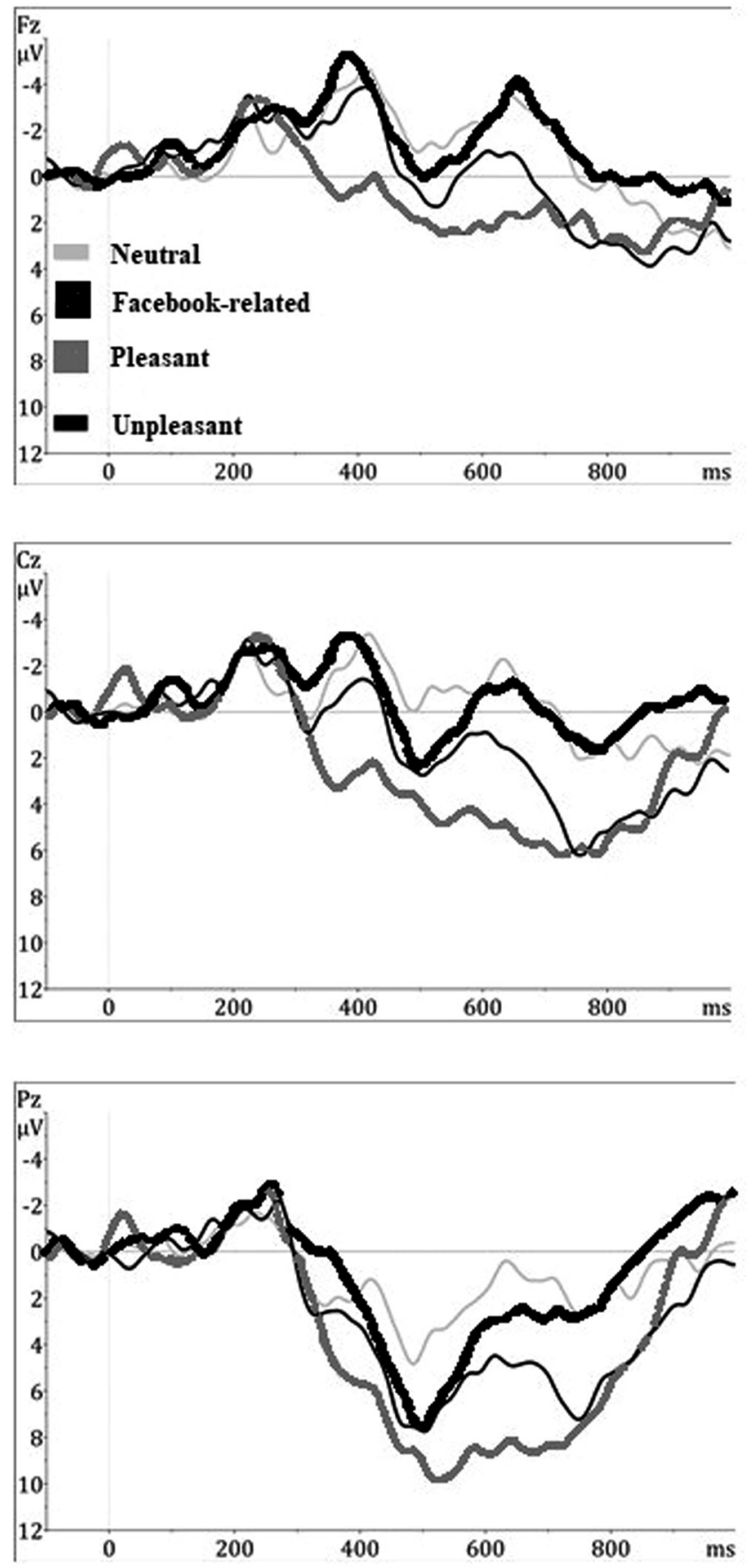

PFUs
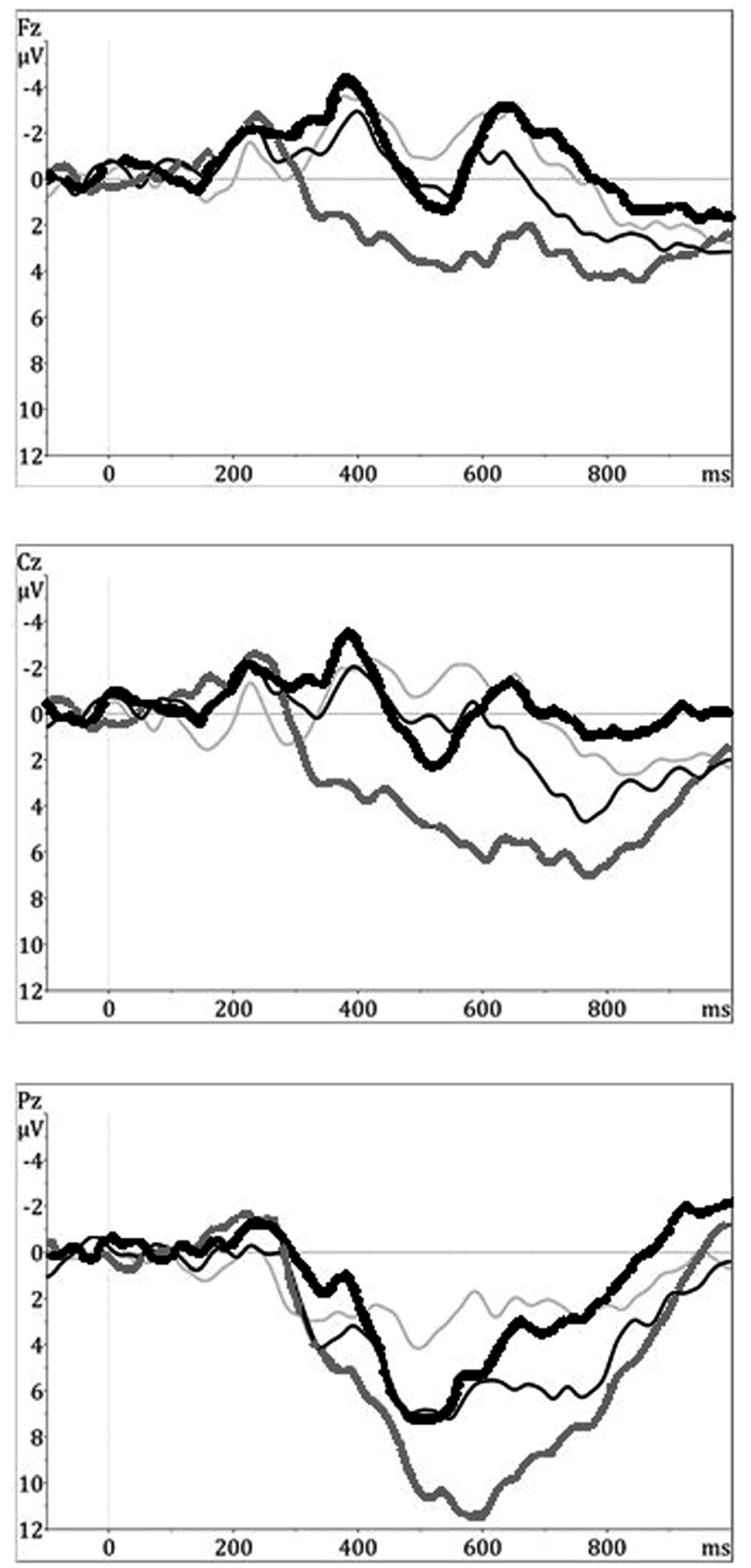

Fig. 1. Grand-average ERPs waveforms recorded at Fz, Cz, and Pz to Neutral, Facebook-related, Pleasant, and Unpleasant pictures in nonPFUs and PFUs

Exploratory analysis: EPN (200-280 ms). A significant main effect of Site $\left(\mathrm{F}_{3,669}=18.04, \mathrm{p}<0.001, \Delta \mathrm{AIC}=35.9\right)$ was found, showing larger relative negativity in $\mathrm{POz}$ than all other channels ( $\mathrm{ps}<0.01$ ). Larger relative negativity was also found in $\mathrm{Oz}$ than $\mathrm{O} 1$ (ps $=0.003$ ), while EPN amplitude was comparable between $\mathrm{O} 2$ and $\mathrm{Oz}$. No other statistically significant within/between or interaction effect was found (Fig. 3).

\section{Valence and Arousal ratings}

The Group main effect was significant only for Valence ratings $\left(\mathrm{F}_{1,51}=4.6, \mathrm{p}=0.04, \Delta \mathrm{AIC}=108\right)$. For both Valence and Arousal ratings, the Category main effect was significant (Arousal: $\mathrm{F}_{3,44}=151.28, \mathrm{p}<0.001, \Delta \mathrm{AIC}=$ 1,264; Valence: $\left.\mathrm{F}_{3,44}=157.1, \mathrm{p}<0.001, \Delta \mathrm{AIC}=1,642\right)$. These effects were specified by the significant 


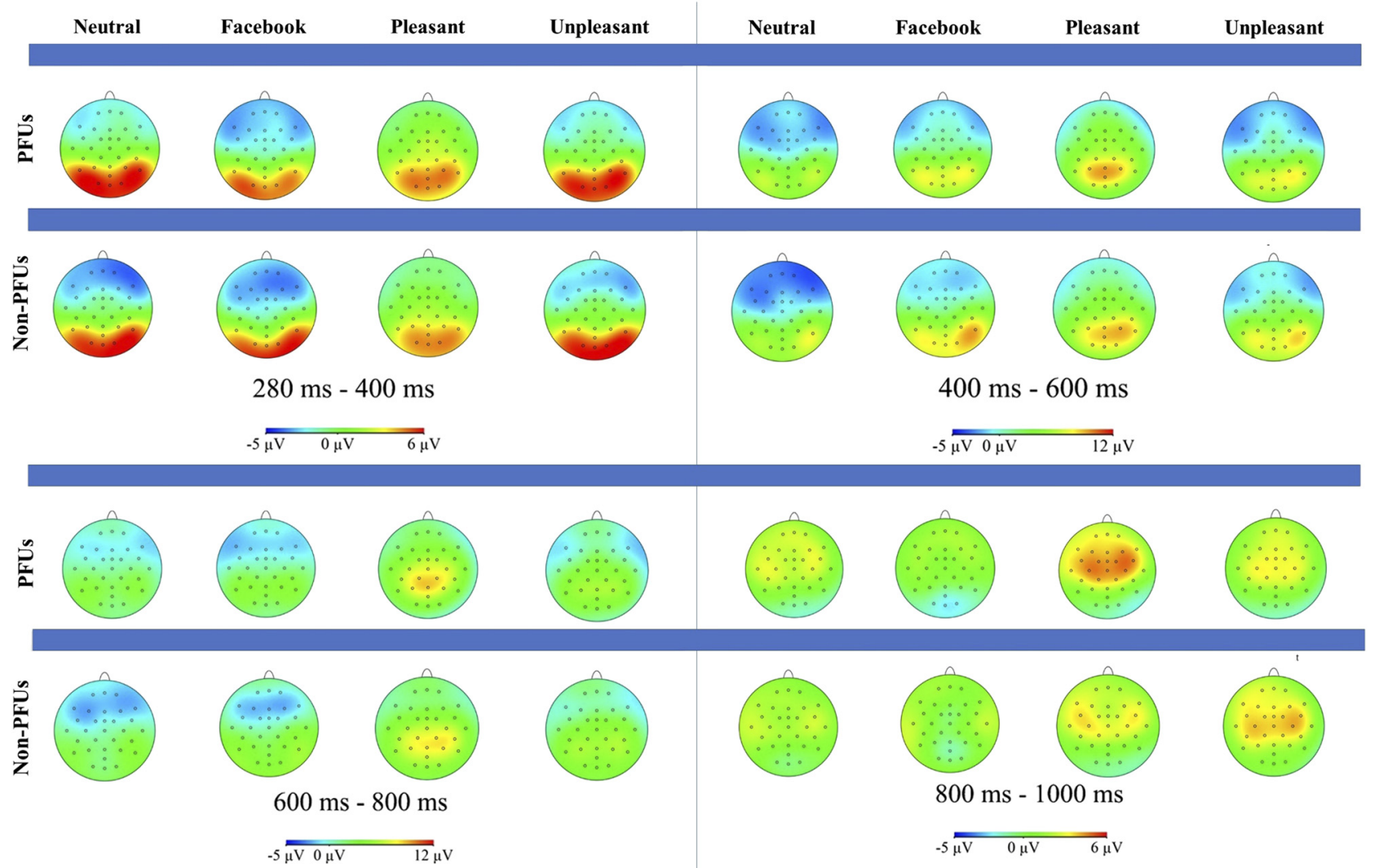

Fig. 2. Scalp topography of Neutral, Facebook-related, Pleasant, and Unpleasant pictures in P3 (280-400 ms), LPP1 (400-600 ms), LPP2 (600-800 ms), and LPP3 (800-1,000 ms) windows in non-PFUs and PFUs

Group $\times$ Category interactions (Arousal: $\mathrm{F}_{3,2441}=5.81, \mathrm{p}<$ $0.001, \Delta$ AIC $=60 ;$ Valence: $\mathrm{F}_{3,2441}=9, \mathrm{p}<0.001, \Delta \mathrm{AIC}=$ 109). As shown in Fig. 4, in both groups Pleasant and Unpleasant pictures elicited significantly greater pleasantness and unpleasantness, respectively, and higher arousal than Neutral and Facebook-related pictures $\left(\mathrm{p}_{\mathrm{s}}<0.001\right)$. No difference between Neutral and Facebook-related pictures was found for Valence ratings. Non-PFUs rated Facebookrelated pictures as significantly less arousing than Neutral pictures $(p=0.02)$, and Unpleasant pictures as significantly more arousing than Pleasant pictures $(\mathrm{p}=0.03)$. As for between-group differences, PFUs rated Facebook-related pictures as significantly more arousing and pleasant than non-PFUs $(p<0.001)$. No between-group differences were found for the other emotional categories.

Pearson's correlations between Valence and Arousal ratings and ERPs in PFUs and non-PFUs are reported in Table 2.

\section{DISCUSSION}

To the best of our knowledge, this is the first study investigating cue-reactivity in PSNSU through ERPs recording. In both groups, Facebook-related pictures triggered greater "motivated" attention/cue-reactivity, as indicated by larger LPP1 amplitude than neutral pictures, and comparable to unpleasant contents. Greater "motivated" attention/cuereactivity in both groups highlight the fact that using SNSs can be highly reinforcing for individuals and reflect liking responses characterizing healthy use or initial stages of problematic use. Although Facebook-related cues do not hold intrinsic motivational significance, they may acquire it by repeated pairing with the potential reinforcing aspects of Facebook usage. Notably, it has been recently shown that with repeated exposure to online social rewards, individuals may become sensitized to their incentive properties, similar to drug users becoming sensitized to drug, with urges to use SNSs (wanting responses) being more related to severe PSNSU than the enjoyment (liking responses) associated with SNSs (Ihssen \& Wadsley, 2021).

This ERP result was not paralleled by subjective ratings of valence and arousal. This is in line with other studies (e.g., Petit, Kornreich, Verbanck, \& Campanella, 2013) and stresses the necessity of using the sensitivity of neuro-imaging techniques to investigate Facebook-related motivational processes that could go unnoticed at the subjective (self-reported) level, in a population as Facebook users, in which abnormalities may not be as marked as in pathological populations.

Interestingly, in both groups, fewer attentional resources were allocated to Facebook-related than to neutral pictures during earlier (P3) processing stages. These findings suggest that independent of problematic use, repeated exposure to 

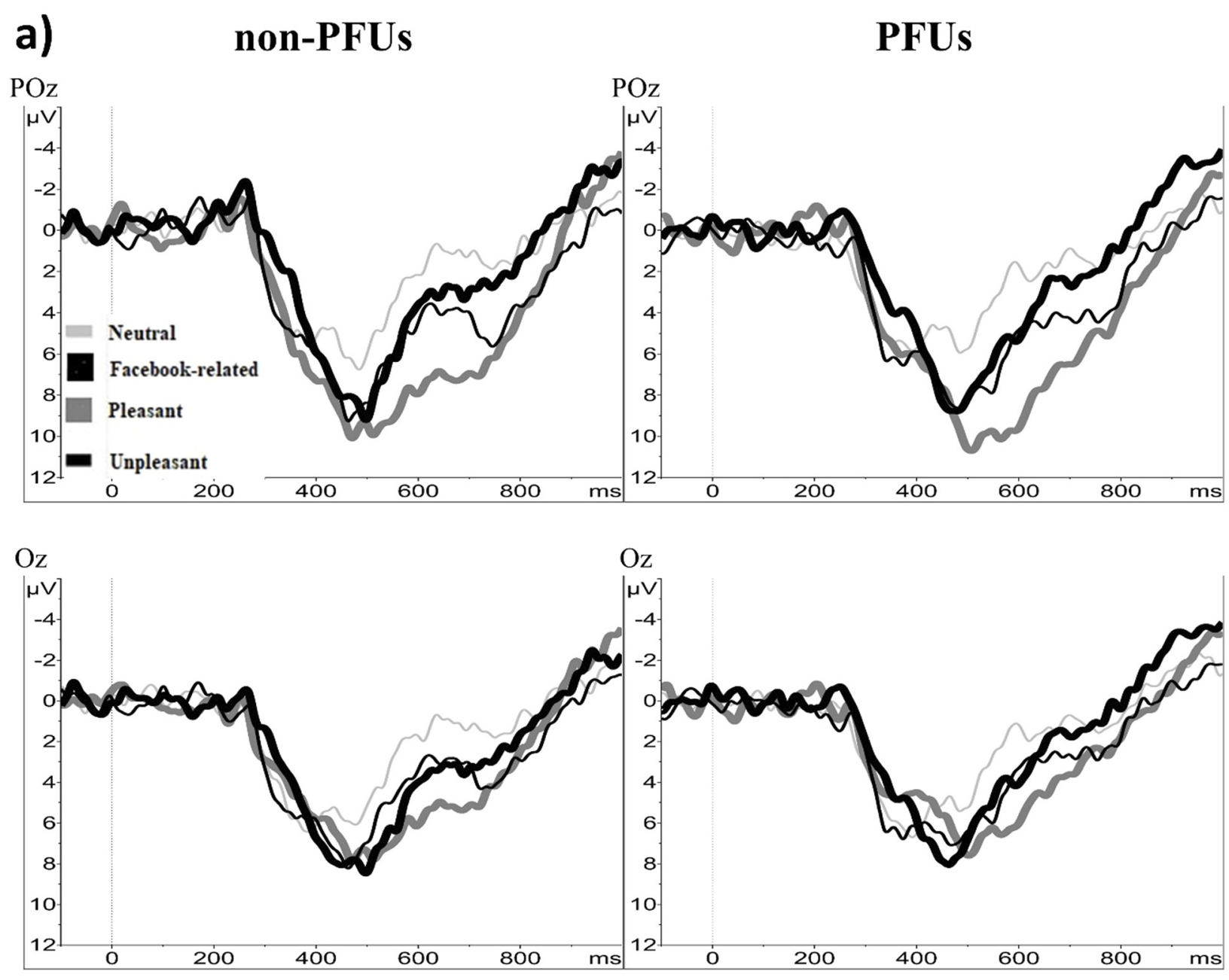

b)

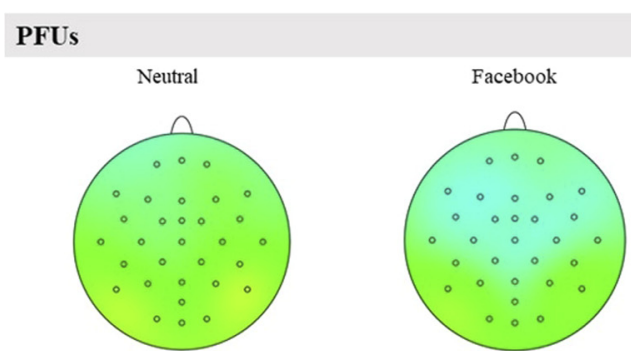

Non-PFUs
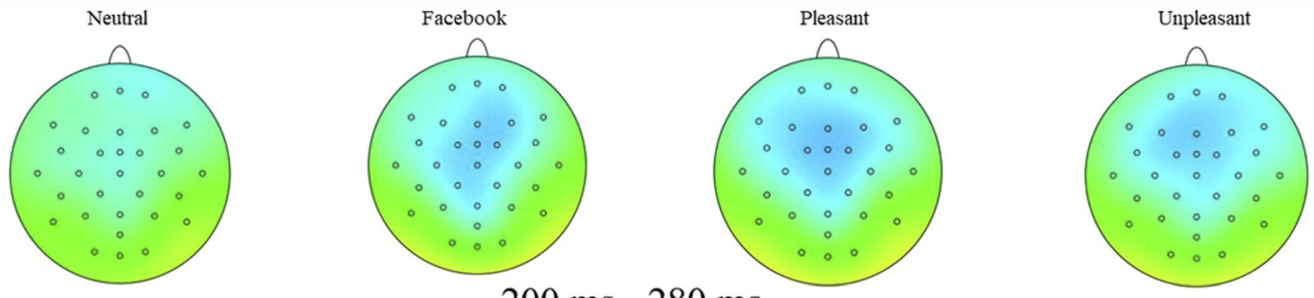

$200 \mathrm{~ms}-280 \mathrm{~ms}$

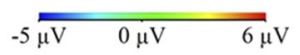

Fig. 3. Grand-average ERPs waveforms recorded at POz and $\mathrm{Oz}$ and scalp topography of Neutral, Facebook-related, Pleasant, and Unpleasant pictures in non-PFUs and PFUs 


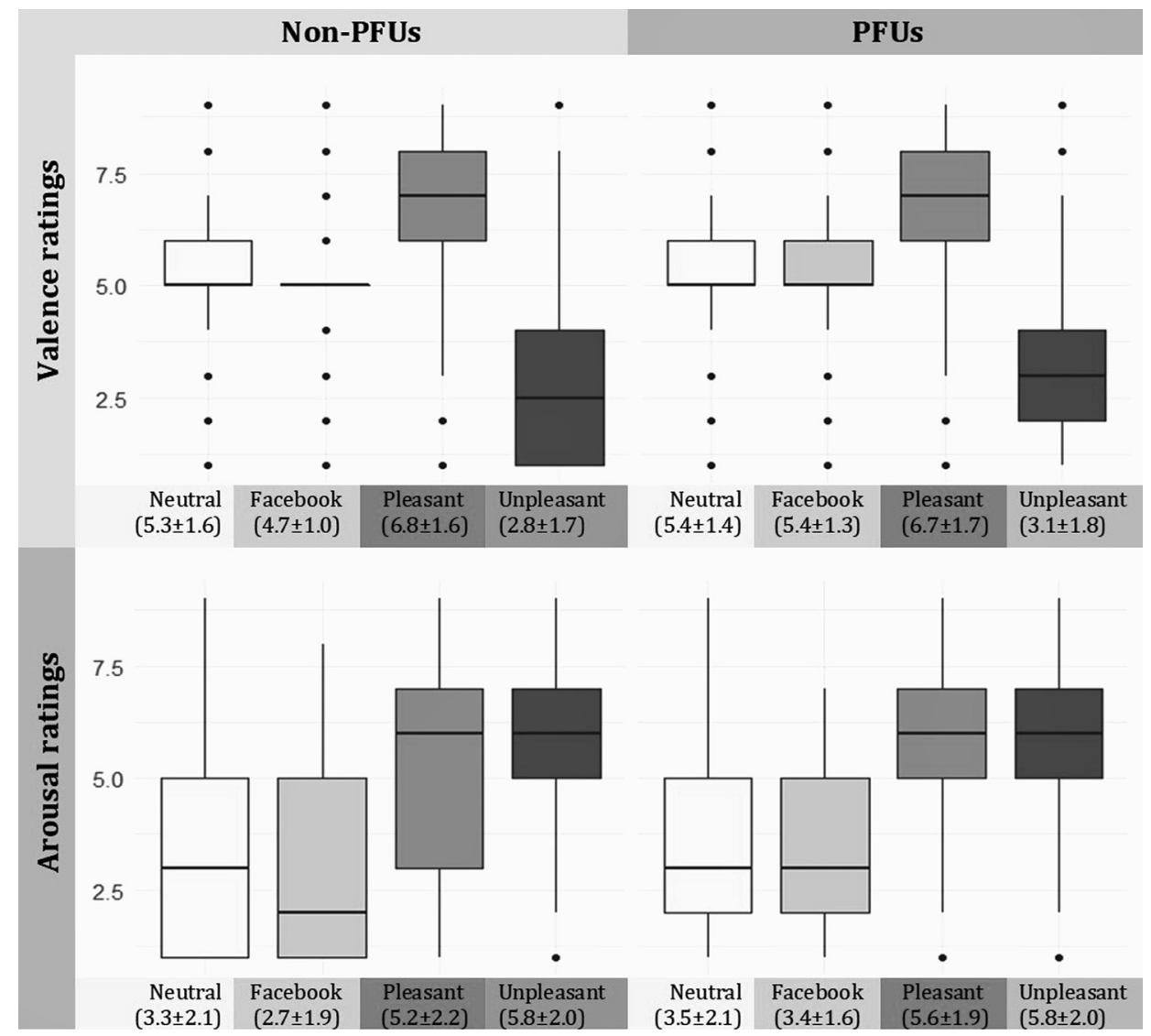

Fig. 4. Valence and Arousal ratings in non-PFUs and PFUs. Mean \pm standard deviation of subjective ratings has been reported for each group and emotional category

Facebook-related stimuli would facilitate associative learning processes leading to overlearned Stimulus-Stimulus associations (S-S). This kind of overlearning process may be generalized to pictures depicting Facebook, which would be perceived as "less new" than neutral ones, affecting earlier attentional deployment. Indeed, P3 has been described to be sensitive to stimulus novelty (Bradley, 2009; van Peer, Grandjean, \& Scherer, 2014). It could be hypothesized that the LPP1 modulation by Facebook-related stimulus significance may be fairly resistant to the overlearned S-S, as indicated by larger amplitude to Facebook-related than neutral pictures (i.e., cue-reactivity) during the central stages of affective processing, i.e., in the LPP1 time window. Of note, as reported in peak analysis in Supplement, the lower P3 amplitude to Facebook-related vs. neutral cues may be specific for PFUs. Further studies are needed to clarify whether possible overlearned S-S associations are common to all users or may be a characteristic of PFUs only.

For none of the considered late ERP components elicited by Facebook-related pictures did the amplitudes in PFUs differ significantly from those in non-PFUs. Therefore, PFUs and non-PFUs allocated similar amounts of attentional resources toward Facebook-related stimuli throughout emotional processing (up to $1,000 \mathrm{~ms}$ ). These findings contrast with previous research in the field of addiction, demonstrating cue-reactivity toward addiction-relevant cues in individuals with SUDs, gambling, gaming, buying disorders, and smartphone addiction compared with controls (Jasinska et al., 2014; Schmitgen et al., 2020; Starcke et al., 2018). However, in the present study, participants were classified as PFUs based on PFUS scores and, unlike participants who received a diagnosis in SUDs and behavioral addiction studies, they may not be fully representative of clinically relevant Facebook-related behaviors. Moreover, cue-reactivity is a complex phenomenon involving multiple components, i.e., reward, learning, memory, attention, and motor processes (Koob \& Volkow, 2016). Such interconnected but different processes may not be equally sensitive in revealing heightened responses to addiction-related cues. That is, although our findings suggest that motivated attention to SNS-related cues is enhanced in both PFUs and non-PFUs, it may be hypothesized that other processes distinguishing PFUs from non-PFUs are affected, e.g., increased motor preparation that might reflect preparation of automated cue-induced behavior (Smolka et al., 2006).

Of note, a group difference emerged for the processing of pleasant contents, with only PFUs showing larger LPP amplitude to pleasant than unpleasant pictures from 600 to $800 \mathrm{~ms}$ post-stimulus, suggesting sustained attention to, and, possibly, delayed disengagement from, pleasant contents in these individuals. This finding fits with those obtained by some studies that suggested exaggerated, rather than 
Table 2. Pearson's (r) correlation coefficients between frontal, central, and parietal midline (Fz, Cz, Pz) P3 and LPP amplitudes and subjective ratings (Arousal and Valence) for each emotional category in problematic (PFUs) and non-problematic Facebook users (nonPFUs). No statistically significant correlation was found

\begin{tabular}{|c|c|c|c|c|c|c|c|c|c|}
\hline & & \multicolumn{8}{|c|}{ PFUs } \\
\hline & & \multicolumn{2}{|c|}{ Facebook-related } & \multicolumn{2}{|c|}{ Neutral } & \multicolumn{2}{|c|}{ Pleasant } & \multicolumn{2}{|c|}{ Unpleasant } \\
\hline & & Arousal & Valence & Arousal & Valence & Arousal & Valence & Arousal & Valence \\
\hline \multirow{3}{*}{$\begin{array}{l}\text { LPP1 }(400-600 \\
\quad \mathrm{ms})\end{array}$} & $\mathrm{Fz}$ & -0.11 & 0.25 & -0.26 & -0.08 & 0.06 & 0.21 & -0.10 & -0.20 \\
\hline & $\mathrm{Cz}$ & -0.30 & 0.24 & -0.31 & 0.01 & 0.26 & 0.33 & -0.05 & -0.02 \\
\hline & $\mathrm{Pz}$ & -0.45 & 0.02 & -0.40 & -0.24 & 0.21 & 0.06 & 0.01 & -0.07 \\
\hline \multirow{3}{*}{$\begin{array}{l}\text { LPP2 (600-800 } \\
\text { ms) }\end{array}$} & $\mathrm{Fz}$ & -0.02 & 0.46 & -0.23 & 0.12 & -0.04 & 0.15 & 0.09 & -0.33 \\
\hline & $\mathrm{Cz}$ & -0.27 & 0.35 & -0.15 & 0.20 & 0.27 & 0.12 & 0.21 & -0.16 \\
\hline & $\mathrm{Pz}$ & -0.35 & 0.03 & -0.32 & -0.05 & 0.36 & -0.27 & 0.32 & -0.08 \\
\hline \multirow{3}{*}{$\begin{array}{l}\text { LPP3 }(800-100 \\
\quad \text { ms) }\end{array}$} & $\mathrm{Fz}$ & -0.15 & 0.05 & -0.19 & 0.12 & 0.10 & -0.07 & 0.26 & -0.19 \\
\hline & $\mathrm{Cz}$ & -0.35 & -0.11 & -0.20 & 0.16 & 0.36 & -0.11 & 0.31 & -0.15 \\
\hline & $\mathrm{Pz}$ & -0.24 & -0.17 & -0.25 & 0.05 & 0.39 & -0.33 & 0.38 & -0.18 \\
\hline \multirow[t]{6}{*}{ P3 } & $\mathrm{Fz}$ & -0.17 & 0.04 & -0.50 & -0.15 & -0.25 & -0.05 & -0.24 & -0.02 \\
\hline & $\mathrm{Cz}$ & -0.25 & 0.04 & -0.48 & -0.03 & -0.19 & 0.14 & -0.24 & 0.05 \\
\hline & $\mathrm{Pz}$ & -0.30 & 0.01 & -0.37 & -0.14 & 0.06 & 0.11 & -0.24 & -0.02 \\
\hline & & \multicolumn{8}{|c|}{ non-PFUs } \\
\hline & & \multicolumn{2}{|c|}{ Facebook-related } & \multicolumn{2}{|c|}{ Neutral } & \multicolumn{2}{|c|}{ Pleasant } & \multicolumn{2}{|c|}{ Unpleasant } \\
\hline & & Arousal & Valence & Arousal & Valence & Arousal & Valence & Arousal & Valence \\
\hline \multirow{3}{*}{$\begin{array}{l}\text { LPP1 (400-600 } \\
\quad \mathrm{ms})\end{array}$} & $\mathrm{Fz}$ & 0.17 & -0.39 & 0.03 & 0.25 & -0.12 & 0.11 & -0.06 & -0.27 \\
\hline & $\mathrm{Cz}$ & 0.16 & -0.46 & 0.08 & 0.22 & -0.14 & 0.10 & -0.02 & -0.34 \\
\hline & $\mathrm{Pz}$ & -0.02 & -0.22 & 0.02 & 0.11 & -0.12 & -0.17 & 0.01 & -0.21 \\
\hline \multirow{3}{*}{$\begin{array}{l}\text { LPP2 (600-800 } \\
\text { ms) }\end{array}$} & $\mathrm{Fz}$ & 0.08 & -0.47 & 0.12 & 0.29 & -0.06 & 0.17 & 0.15 & -0.42 \\
\hline & $\mathrm{Cz}$ & 0.13 & -0.46 & 0.15 & 0.24 & 0.08 & 0.27 & 0.26 & -0.50 \\
\hline & $\mathrm{Pz}$ & 0.19 & -0.30 & 0.04 & 0.28 & 0.13 & 0.08 & 0.27 & -0.40 \\
\hline \multirow[t]{3}{*}{ LPP3 (800-100 ms) } & $\mathrm{Fz}$ & 0.16 & -0.43 & 0.39 & 0.27 & 0.09 & -0.14 & 0.26 & -0.43 \\
\hline & $\mathrm{Cz}$ & 0.17 & -0.48 & 0.28 & 0.29 & 0.26 & -0.01 & 0.37 & -0.49 \\
\hline & $\mathrm{Pz}$ & 0.19 & -0.48 & 0.19 & 0.33 & 0.34 & 0.08 & 0.40 & -0.43 \\
\hline \multirow[t]{3}{*}{ P3 } & $\mathrm{Fz}$ & -0.06 & -0.11 & -0.01 & 0.00 & -0.14 & -0.07 & -0.10 & -0.11 \\
\hline & $\mathrm{Cz}$ & -0.07 & -0.18 & -0.05 & 0.03 & -0.18 & -0.12 & -0.04 & -0.06 \\
\hline & $\mathrm{Pz}$ & -0.20 & 0.06 & -0.10 & 0.03 & -0.18 & -0.17 & -0.14 & 0.18 \\
\hline
\end{tabular}

blunted, reward responsiveness (i.e., larger P3 amplitude to pleasant pictures) to predict the onset of SUDs (e.g., Garfield, Allen, Cheetham, Simmons, \& Lubman, 2015). Importantly, in the later processing stages (800-1,000 ms), higher craving for using Facebook was related to lower LPP to pleasant and unpleasant pictures only in PFUs. This finding suggests that in PFUs who report higher craving ratings, sustained attentional processing of motivationally salient stimuli (natural rewards and threats) unrelated to Facebook cues may be reduced similar to the flattened emotional response to affective pictures (both pleasant and unpleasant) observed in individuals with SUD (VerdejoGarcia, Perez-Garcia, \& Bechara, 2006). It may be speculated that in PFUs who experience more craving, reduced abilities to perceive and experience emotions are the result of defective behavioral flexibility and emotion regulation processes (Brand et al., 2019), that would allow craving states to capture more motivational/attentional resources at the expense of other emotional states. Our results related to the later processing stages of pleasant stimuli are also consistent with theoretical models of SUD claiming that severe addiction symptoms result in the attribution of exaggerated motivational value to addiction-related cues at the expense of naturally rewarding stimuli (e.g., Koob \& Volkow, 2010; Volkow et al., 2010).

In the context of SUD, it has been shown that a pattern characterized by both blunted brain reactivity to pleasant stimuli and enhanced reactivity to addiction-related stimuli would be an accurate metric for identifying individuals who might be at higher risk of relapse (e.g., Dunning et al., 2011; Versace et al., 2012). Our findings seem to suggest that the attribution of motivational value to cues related to social networking sites characterize all kinds of users (resulting in cue-reactivity in both PFUs and non-PFUs). In the later stages of processing, cue-reactivity would occur in conjunction with exaggerated and blunted reward responsiveness as a sign of lower-craving (less severe) and highercraving (more severe) PFUs, respectively. Future studies should further explore the processing of non-addiction relevant pleasant contents in PFUs as a potential risk factor for developing Facebook-related addictive behaviors.

The exploratory analyses revealed that an EPN was not evident following emotional compared to neutral pictures, indicating the lack of an emotional modulation on early 
attentional capture. However, it is important to note that the EPN has not always been observed in emotion research. Several features related to the experimental setup have been suggested to potentially affect the detection of this component (Hajcak \& Dennis, 2009).

Some limitations of the present study should be considered. In addition to the above-mentioned limitation related to the criteria employed for sample selection, a further limitation is represented by the fact that we employed a single-item scale to collect craving ratings (Cano et al., 2014; Dawkins, Munafò, Christoforou, Olumegbon, \& Soar, 2016). Although this is considered a sensitive method to measure craving, the combination with a questionnaire that explores the construct of craving through multiple items would improve the accuracy of the measure (Davey, Barratt, Butow, \& Deeks, 2007). Lastly, our interpretation of ERPs results requires caution as, to the best of our knowledge, there are no published ERPs studies on cue-reactivity in PFU. Further research should be conducted to support our findings.

Funding sources: No financial support was received for this study.

Authors' contribution: TM conceptualized and designed the study, preprocessed data, run statistical analysis, interpreted the results, and wrote the first draft of the manuscript. GB conceptualized and designed the study, interpreted the results, edited the manuscript, and supervised the study. All authors had full access to all data in the study and take responsibility for the integrity of the data and the accuracy of the data analysis.

Conflict of interest: The authors declare no conflict of interest.

Acknowledgments: The present work was carried out within the scope of the research program Dipartimenti di Eccellenza (art.1, commi 314-337 legge 232/2016), which was supported by a grant from MIUR to the Department of General Psychology, University of Padua.

\section{SUPPLEMENTARY MATERIAL}

The online version of this article offers supplementary material https://doi.org/10.1556/2006.2021.00040.

\section{REFERENCES}

Andreassen, C. S., \& Pallesen, S. (2014). Social Network site addiction - An overview. Current Pharmaceutical Design, 20(25), 40534061. https://doi.org/10.2174/13816128113199990616.

Bates, D., Maechler, M., Bolker, B., \& Walker, S. (2014). lme4: Linear mixed-effects models using Eigen and S4. R package version 1.1-7, http://CRAN.R-project.org/package $=$ lme4. $R$ Package Version.

Bradley, M. M. (2009). Natural selective attention: Orienting and emotion. Psychophysiology, 46(1), 1-11. https://doi.org/10.1111/ j.1469-8986.2008.00702.x.

Bradley, M. M., \& Lang, P. J. (1994). Measuring emotion: The selfassessment manikin and the semantic differential. Journal of Behavior Therapy and Experimental Psychiatry, 25(1), 49-59. https://doi.org/10.1016/0005-7916(94)90063-9.

Bradley, M. M., Sabatinelli, D., Lang, P. J., Fitzsimmons, J. R., King, W., \& Desai, P. (2003). Activation of the visual cortex in motivated attention. Behavioral Neuroscience, 117(2), 369-380. https://doi.org/10.1037/0735-7044.117.2.369.

Brand, M., Wegmann, E., Stark, R., Müller, A., Wölfling, K., Robbins, T. W., (2019). The Interaction of Person-AffectCognition-Execution (I-PACE) model for addictive behaviors: Update, generalization to addictive behaviors beyond internet-use disorders, and specification of the process character of addictive behaviors. Neuroscience and Biobehavioral Reviews, 104, 1-10. https://doi.org/10.1016/j.neubiorev.2019. 06.032.

Brand, M., Young, K., Laier, C., Wölfling, K., Potenza, M. N., \& Potenza, M. N. (2016). Integrating psychological and neurobiological considerations regarding the development and maintenance of specific Internet-use disorders: An Interaction of Person-Affect-Cognition-Execution (I-PACE) model. Neuroscience and Biobehavioral Reviews, 71, 252-266. https:// doi.org/10.1016/j.neubiorev.2016.08.033.

Cano, M. Á., Lam, C. Y., Chen, M., Adams, C. E., CorreaFernández, V., Stewart, D. W., ... Wetter, D. W. (2014). Positive smoking outcome expectancies mediate the association between negative affect and smoking urge among women during a quit attempt. Experimental and Clinical Psychopharmacology, 22(4), 332-340. https://doi.org/10.1037/a0036749.

Caplan, S. E. (2010). Theory and measurement of generalized problematic Internet use: A two-step approach. Computers in Human Behavior, 26(5), 1089-1097. https://doi.org/10.1016/ j.chb.2010.03.012.

Carter, B. L., \& Tiffany, S. T. (1999). Meta-analysis of cue-reactivity in addiction research. Addiction, 94(3), 327-340. https://doi. org/10.1046/j.1360-0443.1999.9433273.x.

Christensen, R. H. B. (2015). Ordinal - regression models for ordinal data. In R package version 2015.

Cuthbert, B. N., Schupp, H., Bradley, M. M., Birbaumer, N., \& Lang, P. J. (2000). Brain potentials in affective picture processing: Covariation with autonomic arousal and affective report. Biological Psychology, 52(2), 95-111. https://doi.org/10. 1016/S0301-0511(99)00044-7.

Davey, H. M., Barratt, A. L., Butow, P. N., \& Deeks, J. J. (2007). A one-item question with a Likert or Visual Analog Scale adequately measured current anxiety. Journal of Clinical Epidemiology, 60(4), 356-360. https://doi.org/10.1016/j.jclinepi. 2006.07.015.

Dawkins, L., Munafò, M., Christoforou, G., Olumegbon, N., \& Soar, K. (2016). The effects of e-cigarette visual appearance on craving and withdrawal symptoms in abstinent smokers. Psychology of Addictive Behaviors, 30(1), 101-105. https://doi.org/ 10.1037/adb0000112. 
Dunning, J. P., Parvaz, M. A., Hajcak, G., Maloney, T., Alia-Klein, N., Woicik, P. A., ... Goldstein, R. Z. (2011). Motivated attention to cocaine and emotional cues in abstinent and current cocaine users - an ERP study. European Journal of Neuroscience, 33(9), 1716-1723. https://doi.org/10.1111/j.14609568.2011.07663.x.

Garfield, J. B. B., Allen, N. B., Cheetham, A., Simmons, J. G., \& Lubman, D. I. (2015). Attention to pleasant stimuli in early adolescence predicts alcohol-related problems in mid-adolescence. Biological Psychology, 108, 43-50. https://doi.org/10. 1016/j.biopsycho.2015.03.014.

Griffiths, M. D., Kuss, D., \& Demetrovics, Z. (2014). Social networking addiction. In Behavioral addictions (pp. 119-141). Elsevier. https://doi.org/10.1016/B978-0-12-407724-9.00006-9.

Hajcak, G., \& Dennis, T. A. (2009). Brain potentials during affective picture processing in children. Biological Psychology, 80(3), 333-338. https://doi.org/10.1016/j.biopsycho.2008.11.006.

Hajcak, G., MacNamara, A., \& Olvet, D. M. (2010). Event-related potentials, emotion, and emotion regulation: An integrative review. Developmental Neuropsychology, 35(2), 129-155. https://doi.org/10.1080/87565640903526504.

He, Q., Turel, O., \& Bechara, A. (2017). Brain anatomy alterations associated with Social Networking Site (SNS) addiction. Scientific Reports, 7(1), 45064. https://doi.org/10.1038/srep45064.

Horvath, J., Mundinger, C., Schmitgen, M. M., Wolf, N. D., Sambataro, F., Hirjak, D., .. Christian Wolf, R. (2020). Structural and functional correlates of smartphone addiction. Addictive Behaviors, 105(November 2019), 106334. https://doi.org/10. 1016/j.addbeh.2020.106334.

Hyman, S. E., Malenka, R. C., \& Nestler, E. J. (2006). Neural mechanisms of addiction: The role of reward-related learning and memory. In Annual review of neuroscience (Vol. 29, pp. 565-598). http://ovidsp.ovid.com/ovidweb.cgi?T =JS\&PAGE $=$ reference $\& D=$ emed $7 \& N E W S=N \& A N=2006479352$.

Ihssen, N., \& Wadsley, M. (2021). A reward and incentive-sensitization perspective on compulsive use of social networking sites - wanting but not liking predicts checking frequency and problematic use behavior. Addictive Behaviors, 116, 106808. https://doi.org/10.1016/j.addbeh.2020.106808.

Jasinska, A. J., Stein, E. A., Kaiser, J., Naumer, M. J., \& Yalachkov, Y. (2014). Factors modulating neural reactivity to drug cues in addiction: A survey of human neuroimaging studies. Neuroscience and Biobehavioral Reviews, 38(1), 1-16. https://doi.org/ 10.1016/j.neubiorev.2013.10.013.

Koob, G. F., \& Volkow, N. D. (2010). Neurocircuitry of addiction. Neuropsychopharmacology, 35(1), 217-238. https://doi.org/10. 1038/npp.2009.110.

Koob, G. F., \& Volkow, N. D. (2016). Neurobiology of addiction: A neurocircuitry analysis. The Lancet Psychiatry, 3(8), 760-773. https://doi.org/10.1016/S2215-0366(16)00104-8.

Kuss, D., \& Griffiths, M. D. (2011). Online social networking and addiction-A review of the psychological literature. International Journal of Environmental Research and Public Health, 8(9), 3528-3552. https://doi.org/10.3390/ijerph8093528.

Kuss, D., \& Griffiths, M. D. (2017). Social networking sites and addiction: Ten lessons learned. International Journal of Environmental Research and Public Health, 14(3), 311. https://doi. org/10.3390/ijerph14030311.
Kuznetsova, A., Brockhoff, P. B., \& Christensen, R. H. B. (2017). lmerTest package: Tests in linear mixed effects models. Journal of Statistical Software, 82(13). https://doi.org/10.18637/jss.v082. i13.

Lang, P. J., Bradley, M. M., \& Cuthbert, B. N. (2008). International affective picture system (IAPS): Affective ratings of pictures and instruction manual. In Technical Report A-8.

Leng, Y., He, X., Zhu, B., Li, P., Xiao, C., \& He, W. (2019). The craving and excitement of social networking sites addicts: Based on cue-reactivity. Frontiers in Psychology, 10. https://doi.org/10. 3389/fpsyg.2019.01717.

Littel, M., Euser, A. S., Munafò, M. R., \& Franken, I. H. A. (2012). Electrophysiological indices of biased cognitive processing of substance-related cues: A meta-analysis. Neuroscience and Biobehavioral Reviews, 36(8), 1803-1816. https://doi.org/10. 1016/j.neubiorev.2012.05.001

Luck, S. J. (2014). An introduction to the event-related potential technique, $2^{\text {nd }}$ ed. In The MIT Press.

Marino, C., Vieno, A., Altoè, G., \& Spada, M. M. (2017). Factorial validity of the problematic Facebook use scale for adolescents and young adults. Journal of Behavioral Addictions, 6(1), 5-10. https://doi.org/10.1556/2006.6.2017.004.

Moretta, T., \& Buodo, G. (2018). Modeling Problematic Facebook Use: Highlighting the role of mood regulation and preference for online social interaction. Addictive Behaviors, 87, 214-221. https://doi.org/10.1016/j.addbeh.2018.07.014.

van Peer, J. M., Grandjean, D., \& Scherer, K. R. (2014). Sequential unfolding of appraisals: EEG evidence for the interaction of novelty and pleasantness. Emotion, 14(1), 51-63. https://doi. org/10.1037/a0034566.

Petit, G., Kornreich, C., Verbanck, P., \& Campanella, S. (2013). Gender differences in reactivity to alcohol cues in binge drinkers: A preliminary assessment of event-related potentials. Psychiatry Research, 209(3), 494-503. https://doi.org/10.1016/j. psychres.2013.04.005.

Preacher, K. J., Rucker, D. D., MacCallum, R. C., \& Nicewander, W. A. (2005). Use of the extreme groups approach: A critical reexamination and new recommendations. Psychological Methods, 10(2), 178-192. https://doi.org/10.1037/1082-989X.10.2.178.

R Development Core Team (2016). R: A language and environment for statistical computing. In $\mathrm{R}$ foundation for statistical computing.

Ryan, T., Chester, A., Reece, J., \& Xenos, S. (2014). The uses and abuses of Facebook: A review of Facebook addiction. Journal of Behavioral Addictions, 3(3), 133-148. https://doi.org/10.1556/ JBA.3.2014.016.

Schmitgen, M. M., Horvath, J., Mundinger, C., Wolf, N. D., Sambataro, F., Hirjak, D., .. Wolf, R. C. (2020). Neural correlates of cue reactivity in individuals with smartphone addiction. Addictive Behaviors, 108, 106422. https://doi.org/10.1016/j. addbeh.2020.106422.

Schupp, H., Cuthbert, B., Bradley, M., Hillman, C., Hamm, A., \& Lang, P. (2004). Brain processes in emotional perception: Motivated attention. Cognition and Emotion, 18(5), 593-611. https://doi.org/10.1080/02699930341000239.

Schupp, H., Markus, J., Weike, A. I., \& Hamm, A. O. (2003). Emotional facilitation of sensory processing in the visual cortex. Psychological Science, 14(1), 7-13. https://doi.org/10.1111/14679280.01411. 
Schupp, H., Stockburger, J., Codispoti, M., Junghofer, M., Weike, A. I., \& Hamm, A. O. (2007). Selective visual attention to emotion. Journal of Neuroscience, 27(5), 1082-1089. https://doi.org/10. 1523/JNEUROSCI.3223-06.2007.

Smolka, M. N., Bühler, M., Klein, S., Zimmermann, U., Mann, K., Heinz, A., \& Braus, D. F. (2006). Severity of nicotine dependence modulates cue-induced brain activity in regions involved in motor preparation and imagery. Psychopharmacology, 184(3-4), 577-588. https://doi.org/10.1007/s00213-005-0080-x.

Starcke, K., Antons, S., Trotzke, P., \& Brand, M. (2018). Cuereactivity in behavioral addictions: A meta-analysis and methodological considerations. Journal of Behavioral Addictions, 7(2), 227-238. https://doi.org/10.1556/2006.7.2018.39.

Turel, O., He, Q., Xue, G., Xiao, L., \& Bechara, A. (2014). Examination of neural systems sub-serving Facebook "addiction." Psychological Reports, 115(3), 675-695. https://doi.org/10.2466/ 18.PR0.115c31z8.

Verdejo-Garcia, A., Perez-Garcia, M., \& Bechara, A. (2006). Emotion, decision-making and substance dependence: A somatic-marker model of addiction. Current Neuropharmacology, 4(1), 17-31. https://doi.org/10.2174/157015906775203057.

Versace, F., Engelmann, J. M., Deweese, M. M., Robinson, J. D., Green, C. E., Lam, C. Y., . . Cinciripini, P. M. (2017). Beyond cue reactivity: Non-drug-related motivationally relevant stimuli are necessary to understand reactivity to drug-related cues. Nicotine and Tobacco Research, 19(6), 663-669. https://doi.org/10.1093/ntr/ntx002.

Versace, F., Lam, C. Y., Engelmann, J. M., Robinson, J. D., Minnix, J. A., Brown, V. L., \& Cinciripini, P. M. (2012). Beyond cue reactivity: Blunted brain responses to pleasant stimuli predict long-term smoking abstinence. Addiction Biology, 17(6), 9911000. https://doi.org/10.1111/j.1369-1600.2011.00372.x.

Versace, F., Minnix, J. A., Robinson, J. D., Lam, C. Y., Brown, V. L., \& Cinciripini, P. M. (2011). Brain reactivity to emotional, neutral and cigarette-related stimuli in smokers. Addiction Biology, 16(2), 296-307. https://doi.org/10.1111/j.1369-1600. 2010.00273.x.

Volkow, N. D., Wang, G.-J., Fowler, J. S., Tomasi, D., Telang, F., \& Baler, R. (2010). Addiction: Decreased reward sensitivity and increased expectation sensitivity conspire to overwhelm the brain's control circuit. BioEssays, 32(9), 748-755. https://doi. org/10.1002/bies.201000042.

Wagenmakers, E.-J., \& Farrell, S. (2004). AIC model selection using Akaike weights. Psychonomic Bulletin and Review, 11(1), 192196. https://doi.org/10.3758/BF03206482.

Wegmann, E., \& Brand, M. (2019). A narrative overview about psychosocial characteristics as risk factors of a problematic social networks use. Current Addiction Reports, 6(4), 402-409. https://doi.org/10.1007/s40429-019-00286-8.

Wegmann, E., Ostendorf, S., \& Brand, M. (2018). Is it beneficial to use Internet-communication for escaping from boredom? Boredom proneness interacts with cue-induced craving and avoidance expectancies in explaining symptoms of Internetcommunication disorder. PloS One, 13(4), e0195742. https:// doi.org/10.1371/journal.pone.0195742.

Wegmann, E., Stodt, B., \& Brand, M. (2018). Cue-induced craving in Internet-communication disorder using visual and auditory cues in a cue-reactivity paradigm. Addiction Research and Theory, 26(4), 306-314. https://doi.org/10.1080/16066359.2017.1367385. 